\title{
Editorial: The First Four Years (2013-2016) of Life: The Excitement of Biology
}

\author{
Jorge A. Santiago-Blay ${ }^{1}$
}

This is my annual summary of the major developments of Life: The Excitement of Biology, emphasizing 2016 and, thereafter, I ponder about the roles of $\boldsymbol{L E B}$.

\section{Main Developments}

1. Expanded Indexing and Referencing. Life: The Excitement of Biology continues to be indexed and its published articles detected by Biosis Previews, Biological Abstracts, CAB Abstracts, EBSCOhost Academic Search Ultimate, Google Scholar, Research Gate, Ulrich, and Zoological Record. Basch Subscriptions continues including $\boldsymbol{L E B}$ in their online platform database. Life: The Excitement of Biology continues participating fully in CitedBy. Other requests for inclusion are currently being considered.

2. Increased Internationalization. More scholars joined the Board of Editors of Life: The Excitement of Biology during 2016. Currently, the board has over 100 members representing over 40 countries worldwide.

3. New Web Page and Continued "Responsive" Presence via Social Media. The newly-designed website of Life: The Excitement of Biology is compatible with diverse types of mobile devices and screen sizes. Also, $\boldsymbol{L E B}$ continues having a strong digital presence through our digital carrier, WordPress and maintains a regular presence, particularly through Facebook, LinkedIn, and Twitter, Tumblr, among others.

4. Constant Improvements. Authors, reviewers, subscribers, and members of the boards of Life: The Excitement of Biology continue suggesting improvements to the journal many of which we have gratefully incorporated. This editor insists that all scientific papers submitted to $\boldsymbol{L E B}$ be peer-reviewed while colleagues doing the reviews are encouraged to be careful, constructive, and as fast as possible.

\section{Roles of Life: The Excitement of Biology in society at large}

Life: The Excitement of Biology has a dual mission. First, serving as a reputable, peer-reviewed, international venue to the scientific community. Second, to communicate science to a broad audience. From time to time, I interact

\footnotetext{
${ }^{1} 217$ Wynwood Road, York, Pennsylvania 17402 USA. E-mail: blayjorge@ gmail.com
} 
with colleagues whose views on the nature of science communication seem to differ markedly with those of mine. As typical of me, I mull over the interaction, take what I consider worthy and move on. However, some other interactions are so surprising and/or interest that I bounce them off members of the board. Below, I quote what three colleagues communicated to me because of my inquiries about science communication.

1. "Good science that everyone can understand is an important goal for $\boldsymbol{L E B}$ and for all of us."

2. "We see this in 'name of the country' as well. Elitism in science reduces the spread of what we do to the broad public who, after all, should be the destination of the information we generate as they pay our salaries and research funding." (Translated from Spanish.)

3. "This is a subject I feel very strongly about! I think that we have a duty as scientists to report our findings in the most accessible way so that the information can, in principle, be understood by the widest possible readership. Of course, it can turn out that specialized terminology is a barrier to some readers but we should not assume that people without formal qualifications would not be able to look up words they are not familiar with. Despite the challenging vocabulary, science should be for everybody and we should work as hard as possible not to be elitist. Two personal observations. When I was a child my father had a book, called Science for the Citizen which addressed complex issues in science but was directed towards an adult audience with good reading ability but little formal education (like my father). I have always respected the intentions of that book and felt that there is an obligation for scientists to reach the widest audience and not to categorize people into those who might understand and those who might not. In my experience, many people have a desire to learn about many things in the world that are not part of their formal study or education but simply represent curiosity - one of the finest characteristics of our species."

\section{Despite unexpected adversity, we persevered with gratefulness}

Towards the end of 2016, something I had never experienced in my editorial career (2000 to the present) occurred. Although plenty of papers were received for consideration for publication in $\boldsymbol{L E B}$ 4(4), two papers were withdrawn - one after acceptance as well as extensive editorial work and assistance to the authors; two others were rejected; and the author of a fifth paper was hospitalized rendering the author unable to complete the paper in a timely fashion. Yet, this seemingly unbelievable string of mishaps somehow gave me greater strength to persevere! Life: The Excitement of Biology 4(4) was late; LEB 5(1) appeared, and I hope $\boldsymbol{L E B} 5(2)$ will resume our generally on time publication.

Our progress since 2013 could not have been possible without the numerous fruitful communications with members of the board of editors of Life: The Excitement of Biology. Also, I wish to warmly extend a welcome to Wolf Printing of York, Pennsylvania (USA), the new printers of the hard copy version of Life: 
The Excitement of Biology as well as to WordPress, carrier of the digital version of $\boldsymbol{L E B}$ and their friendly and helpful online staff members who deserve a special recognition.

Please, feel free to spread the word about Life: The Excitement of Biology and its high quality, fast publication, and helpfulness; a terrific value, in sum, science for all. I hope all of you join me in a wonderful voyage of discovery during 2017.

Sincerely and gratefully,

Jorge Santiago-Blay

Jorge Santiago-Blay, Ph.D.

Editor-in-Chief, Life: The Excitement of Biology

E-mail: blaypublishers@gmail.com

Facebook: Jorge A. Santiago-Blay

LinkedIn: Jorge Santiago-Blay

Twitter: @blayjorge

Tumblr: Life-The Excitement of Biology

WordPress: Life-The Excitement of Biology

$* * *$

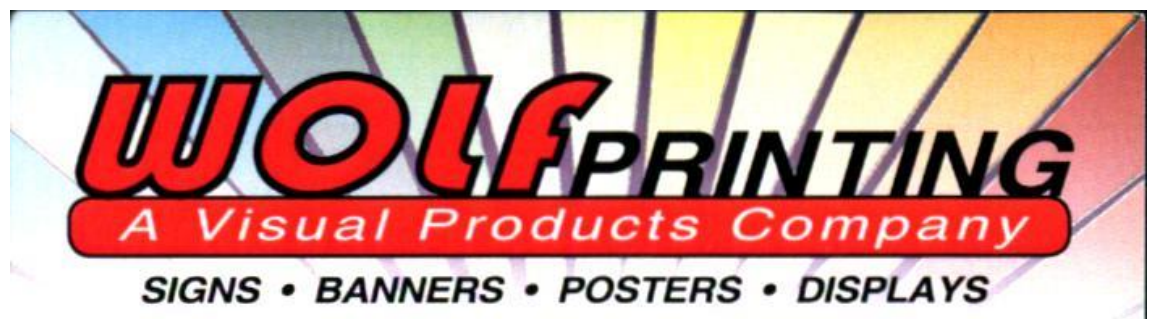

1200 Haines Road, York, PA 17402

717.755.1560 • 717.840.0496 FAX

sales@wolfprinting.com

\section{www.wolforinting.com}

